\title{
Heart failure modulates electropharmacological characteristics of sinoatrial nodes
}

\author{
SHIH-LIN CHANG ${ }^{1,2^{*}}$, HUI-LUN CHUANG ${ }^{1,3^{*}}$, YAO-CHANG CHEN ${ }^{4}$, YU-HSUN KAO ${ }^{5,6}$, \\ YUNG-KUO LIN ${ }^{6,7}$, YUNG-HSIN YEH ${ }^{8}$, SHIH-ANN CHEN ${ }^{1,2}$ and YI-JEN CHEN ${ }^{6,7}$ \\ ${ }^{1}$ Division of Cardiology, Taipei Veterans General Hospital; Departments of ${ }^{2}$ Medicine and ${ }^{3}$ Physiology, \\ National Yang-Ming University School of Medicine, Taipei 112; ${ }^{4}$ Department of Biomedical Engineering, \\ National Defense Medical Center, Taipei 114; ${ }^{5}$ Department of Medical Education and Research, Wan Fang Hospital, \\ Taipei Medical University, Taipei 116; ${ }^{6}$ Graduate Institute of Clinical Medicine, College of Medicine, \\ Taipei Medical University, Taipei 110; ${ }^{7}$ Division of Cardiovascular Medicine, Department of Internal Medicine, \\ Wan Fang Hospital, Taipei Medical University, Taipei 116; ${ }^{8}$ The First Cardiovascular Division, \\ Chang-Gung Memorial Hospital and Chang-Gung University, Tao-Yuan 244, Taiwan, R.O.C.
}

Received September 17, 2015; Accepted October 20, 2016

DOI: $10.3892 /$ etm.2016.4015

\begin{abstract}
The impact of heart failure (HF) on sinoatrial node (SAN) channel regulation and electropharmacological responses has remained elusive. The present study aimed to investigate the effects of HF on the electrical activity of SANs with and without pharmacological interventions. Action potentials (APs) were recorded in isolated SANs from normal rabbits (control) and those with HF (rapid ventricular pacing for 4 weeks) prior to and after administration of a funny current blocker (ivabradine; $0.1,0.3,3$ or $10 \mu \mathrm{M}$ ), a calmodulin kinase II inhibitor (KN-93; 0.3 or $3 \mu \mathrm{M})$, a sarcoplasmic reticulum $\mathrm{Ca}^{2+}$ release inhibitor (ryanodine; 0.3 or $3 \mu \mathrm{M}$ ), a sodium current inhibitor (tetrodotoxin; 1,3 or $10 \mu \mathrm{M}$ ) and a late sodium current inhibitor (ranolazine; $10 \mu \mathrm{M}$ ). Western blot analysis was used to investigate the protein expression in SANs from normal rabbits and those with HF. Control SANs had a higher beating rate than SANs from rabbits with HF (2.3 \pm 0.1 vs. $1.5 \pm 0.1 \mathrm{~Hz} ; \mathrm{P}<0.001)$. Similarly, ivabradine $(10 \mu \mathrm{M}), \mathrm{KN}-93(3 \mu \mathrm{M})$, ranolazine $(10 \mu \mathrm{M})$ and ryanodine $(3 \mu \mathrm{M})$ decreased the beating rates of SANs in the control $(\mathrm{n}=6)$
\end{abstract}

Correspondence to: Dr Yi-Jen Chen, Division of Cardiovascular Medicine, Department of Internal Medicine, Wan Fang Hospital, Taipei Medical University, 111 Hsin-Lung Road, Sec. 3, Taipei 116, Taiwan, R.O.C.

E-mail: yjchen@tmu.edu.tw

Dr Shih-Ann Chen, Division of Cardiology, Taipei Veterans General Hospital, 201 Sec. 2, Shih-Pai Road, Taipei 112, Taiwan, R.O.C.

E-mail: epsachen@ms41.hinet.net

*Contributed equally

Key words: ivabradine, $\mathrm{KN}-93$, heart failure, ryanodine, tetrodotoxin, ranolazine and HF ( $n=6)$ groups. Ivabradine treatment resulted in a higher incidence of AP block in HF vs. control SANs (66.7 vs. 0\%; $\mathrm{P}<0.05)$. Tetrodotoxin $(1,3$ or $10 \mu \mathrm{M})$ decreased the beating rate to a higher extent in SANs from rabbits with HF than in those from control rabbits and induced a higher incidence of AP block (66.7 vs. 0\%; P<0.05). Furthermore, SANs from rabbits with $\mathrm{HF}$ had higher protein levels of phospholamban (PLB) and lower levels of hyperpolarization-activated cyclic nucleotide-gated potassium channel 4 , ryanodine receptor and phosphorylated PLB than control SANs. In conclusion, HF modulates electropharmacological responses in the SAN by channel regulation, which may result in SAN dysfunction.

\section{Introduction}

Heart failure (HF) is a major cardiovascular disease whose incidence is increasing and which remains a leading cause of mortality worldwide. Patients with HF have significant sinoatrial node (SAN) remodeling characterized by anatomic and structural changes with a reduction in functional sinus node reserve (1). HF causes extensive remodeling of ionic and gap junction channels in the SAN (2), which is associated with SAN dysfunction, leading to bradycardia and mortality (3-5). HF doubles the SAN recovery time and suppresses hyperpolarization-activated cyclic nucleotide-gated potassium channel (HCN) expression of the SAN at the mRNA and protein level (6). Modulation of HCN subunit expression may be an important contributor to SAN dysfunction and atrial dysrhythmias in HF. Moreover, several novel ionic channel blockers have been applied for the treatment of HF. Ivabradine, a specific inhibitor of the pacemaker current $\left(I_{\mathrm{f}}\right)$ in the SAN, was shown to significantly reduce major risks associated with $\mathrm{HF}$ when added to guideline-based treatment (7). However, it has remained elusive whether HF changes the pharmacological responses in the SAN.

SAN dysfunction in HF is associated with suppression of rhythmic spontaneous sarcoplasmic reticulum $\mathrm{Ca}^{2+}$ release 
$\left(\mathrm{Ca}^{2+}\right.$ clock), resulting in unresponsiveness of the SAN to isoprotenrenal and caffeine (8). Oxidized calmodulin kinase II (ox-CaMKII) was shown to be a biomarker for SAN dysfunction in humans and dogs, which triggered SAN cell apoptosis (9). A CaMKII inhibitor was shown to improve cardiac function and suppress arrhythmias (10). Stabilization of the ryanodine receptor (RyR) decreases intracellular $\mathrm{Ca}^{2+}$ leakage and improves diastolic and systolic function, and is a potential treatment strategy for HF (11-13). However, the effects of CaMKII inhibitors on the SAN in the presence or absence of HF have remained elusive.

The center of the node contains few or no $\mathrm{Na}^{+}$channels; furthermore, block of the $\mathrm{Na}^{+}$channel decreases the beating rate of the SAN by approximately one-third and prolongs its conduction time. A simulation study showed that mutations of the SCN5A gene led to SAN dysfunction (14). Loss-of-function $\mathrm{Na}^{+}$-channel mutations were reported to impair the SAN pacemaker and conduction functions through a combination of augmented tail and reduced peak $\mathrm{Na}^{+}$currents $\left(I_{\mathrm{Na}}\right)(15)$. A reduced $I_{\mathrm{Na}}$ and increased late $I_{\mathrm{Na}}$ $\left(I_{\text {Na-Late }}\right)$ were found in ventricular cardiomyocytes from dogs with pacing-induced HF, which may cause prolongation of action potentials (APs) and the genesis of arrhythmias (16). Ranolazine, an inhibitor of the $I_{\text {Na-Late }}$, is a potent anti-ischemic and anti-anginal agent, which exerts beneficial effects in patients with HF in clinical practice $(17,18)$. This drug is a promising pharmacological agent for treating HF. However, certain adverse events associated with sinus bradycardia are of concern due to the poor understanding of the pharmacological effects of these novel ionic channel blockers on the electrophysiology of SANs from patients with HF. The aim of the present study was therefore to investigate whether HF modulates the electropharmacological responses of SANs by channel regulation.

\section{Materials and methods}

Animal model of HF. The present study conformed to guidelines of the US National Institutes of Health and the European Commission. The study protocol was reviewed and approved by the Institutional Animal Care and Use Committee of Taipei Veterans General Hospital (Taipei, Taiwan). Male New Zealand white rabbits ( $\mathrm{n}=12$; weight, $2-3 \mathrm{~kg}$; age, 6-8 months) were used in the present study. Rabbits had ad libitum access to food and water, were maintained in a temperature and humidity-controlled environment $\left(20-22^{\circ} \mathrm{C} ; 50-70 \%\right.$ humidity) with a 12-h light/dark cycle, and were raised in stainless steel cages. In the experimental group of rabbits $(n=6), \mathrm{HF}$ was induced by rapid ventricular pacing (360-400 bpm) for 4 weeks through programmable right ventricular pacemakers (Sigma SS303; Medtronic, Minneapolis, MN, USA), implanted as described previously $(19,20)$, while animals in the control group $(n=6)$ were left untreated. At the end of the 4 weeks of ventricular tachypacing, $\mathrm{HF}$ was confirmed by clinical signs (ascites, edema, drowsiness and dyspnea). The left ventricular ejection fraction (LVEF) was measured in the parasternal long-axis view. In the HF rabbits, the LVEF was decreased from $77.8 \pm 2.3$ to $39.2 \pm 2.5 \%$ ( $\mathrm{P}<0.001$, baseline vs. HF). The echocardiographic data of the normal (control) and HF rabbits are provided in Table I.
After rabbits were anesthetized by an intraperitoneal injection of sodium pentobarbital (100 mg/kg; Sigma-Aldrich; Merck Millipore, Darmstadt, Germany) a midline thoracotomy was performed, and the heart and lungs were removed. The right atrium (RA) preparation, including the SAN and crista terminalis, was isolated and immersed in normal Tyrode's solution consisting of $137 \mathrm{mM} \mathrm{NaCl}, 4 \mathrm{mM} \mathrm{KCl}, 15 \mathrm{mM}$ $\mathrm{NaHCO}_{3}, 0.5 \mathrm{mM} \mathrm{NaH} \mathrm{PO}_{4}, 0.5 \mathrm{mM} \mathrm{MgCl}, 2.7 \mathrm{mM} \mathrm{CaCl}$ and $11 \mathrm{mM}$ dextrose. The SAN was identified as a whitish endocardial region near the junction of the RA-free wall and atrial appendage near the crista terminalis (21).

Electropharmacological study. Transmembrane APs of the SANs were recorded from isolated SAN preparations by conventional glass electrodes at baseline [0.03\% dimethyl sulfoxide (DMSO) as vehicles], in the presence of $0.01 \%$ acetic acid or after drug administration of a funny current blocker (ivabradine, $0.1,0.3,3$ or $10 \mu \mathrm{M}$ in $0.03 \%$ DMSO), CaMKII inhibitor (KN-93, 0.3 or $3 \mu \mathrm{M}$ in $0.03 \%$ DMSO), SR Ca ${ }^{2+}$ release inhibitor (ryanodine, 0.3 or $3 \mu \mathrm{M}$ ), sodium current inhibitor [tetrodotoxin (TTX), 1,3 or $10 \mu \mathrm{M}$ in $0.01 \%$ acetic acid) and late sodium current inhibitor (ranolazine, $10 \mu \mathrm{M}$ ). Details of this method were described in previous studies by our group $(22,23)$. One end of the preparation was pinned to the bottom of a tissue bath, while the other end was connected to a Grass FT03C force transducer (Natus Medical, Inc., Pleasanton, CA, USA) with silk thread. The endocardium of the preparations faced upwards. The tissue was superfused at a constant rate $(3 \mathrm{ml} / \mathrm{min}$ ) with Tyrode's solution saturated with a $97 \% \mathrm{O}_{2}-3 \% \mathrm{CO}_{2}$ gas mixture. The temperature was maintained at $37^{\circ} \mathrm{C}$ and the preparations were allowed to equilibrate for $1 \mathrm{~h}$ prior to the electrophysiological study. Transmembrane APs were recorded by glass capillary microelectrodes filled with $3 \mathrm{M} \mathrm{KCl}$ that were connected to a FD223 electrometer (World Precision Instruments, LLC, Sarasota, FL, USA). Electrical and mechanical events were simultaneously displayed on a Gould 4072 oscilloscope and a Gould TA11 recorder (Gould Instrument Systems, Inc., Cleveland, OH, USA). The signal was recorded with DC coupling and a $10-\mathrm{kHz}$ low-pass filter cutoff frequency using a data-acquisition system. The amplitude of the AP (APA), the maximum diastolic potential (MDP) and the diastolic depolarization rate (DDR, measured over a 50-msec time interval starting at the MDP) were measured only during the steady-state AP achieved without interference by spontaneous activity. AP parameters from 10 consecutive action potentials were averaged. AP block was defined as an AP with incomplete morphology and a lower amplitude compared that at baseline during the steady-state recording (24).

Western blot analysis. For western blot analysis, SAN tissues were isolated from control and HF groups with confirmation by morphology of the AP using conventional glass electrodes. Samples were suspended in lysis buffer containing $50 \mathrm{mM}$ Tris ( $\mathrm{pH} 7.4$ ), $150 \mathrm{mM} \mathrm{NaCl}, 1 \%$ Nonidet P-40, $0.5 \%$ sodium deoxycholate, $0.1 \%$ sodium dodecylsulfate (SDS), $20 \mathrm{mM}$ $\mathrm{NaF}, 2 \mathrm{mM} \mathrm{Na}_{3} \mathrm{VO}_{4}$ and protease inhibitor cocktail (Sigma; Merck Millipore). A Bradford assay was used to determine the protein concentration in homogenates and $40 \mu \mathrm{g}$ of the total protein were loaded for each sample. Proteins were separated by $5 \%$ (RyR), $15 \%$ [total and phosphorylated phospholamban 
(PLB)] or $8 \%$ [HCN4, CaMKII, sarcoplasmic reticulum $\mathrm{Ca}^{2+}$-ATPase (SERCA2a), and Nav1.5] SDS-polyacrylamide gel electrophoresis under reducing conditions and electrophoretically transferred into an equilibrated polyvinylidene difluoride membrane (Amersham Biosciences, GE Healthcare, Chalfont, UK). Blots were probed with primary antibodies against HCN4 (AB5808; 1:500; Millipore, Billerica, MA, USA), CaMKII (ab54927; 1:500; Abcam, Cambridge, UK), SERCA2a (sc-8095; 1:2,000; Santa Cruz Biotechnology, Inc., Dallas, TX, USA), phospholamban (PLB; MA3-922; 1:2,000; Thermo Fisher Scientific, Inc.), PLB-T17 (A010-13; 1:5,000; Badrilla, Leeds, UK), RyR (MA3-916; 1:1,000; Thermo Fisher Scientific, Inc.), Nav1.5 (AB5493; 1:1,000; Millipore), and one of the following secondary antibodies conjugated to horseradish peroxidase for $1 \mathrm{H}$ at room temperature: Goat anti-Rabbit (AP132P; 1:20,000, Millipore), donkey anti-sheep/goat (AB324P; 1:8,000; Millipore), or goat anti-Mouse (AP124P; 1:8,000; Millipore). Bound antibodies were detected with a Luminata Forte Western HRP substrate (WBLUF0500; Millipore) and analyzed with Image-Pro Plus software (version 6.0; Media Cybernetics, Rockville, MD, USA). Targeted bands were normalized to cardiac $\alpha$-sarcomeric actin (A2172; 1:2,000; Sigma; Merck Millipore) to confirm equal protein loading.

Statistical analysis. All continuous variables are expressed as the mean \pm standard error of the mean. A one-way repeated-measures analysis of variance followed by a Bonferroni analysis was used to compare differences prior to and after drug administration in control and HF SANs. The extent of reduction of the SAN after drug infusion and the protein expression of ionic currents between the control and HF groups were compared by a Wilcoxon rank-sum test or unpaired t-test depending on the outcome of the normality test. A Chi-squared test with Fisher's exact test was used to compare the incidence of SAN AP block between the control and HF groups. Statistical analyses were performed using SigmaStat software (version 3.5; Systat Software, Inc., San Jose, CA, USA). $\mathrm{P}<0.05$ was considered to indicate a statistically significant difference.

\section{Results}

HF affects electropharmacological responses of SANs. The effects of Ivabradine on SANs are shown in Fig. 1A-D. SANs from the control group had a higher beating rate than those in the $\mathrm{HF}$ group $(2.3 \pm 0.1$ vs. $1.5 \pm 0.1 \mathrm{~Hz} ; \mathrm{P}<0.001)$. Ivabradine at 3 and $10 \mu \mathrm{M}$ decreased the beating rates of SANs in the control group (Fig. 1A and B), but only decreased those in the $\mathrm{HF}$ group at $10 \mu \mathrm{M}$ (Fig. $1 \mathrm{C}$ and D). At $10 \mu \mathrm{M}$, ivabradine decreased the beating rate in the control and HF groups to a similar extent $(26 \pm 5$ vs. $29 \pm 10 \%$; P>0.05). Ivabradine did not affect the APA or MDP in control or HF SANs (Fig. 1B). Higher doses of ivabradine ( 3 and $10 \mu \mathrm{M}$ ) decreased the DDR in the control and HF SANs (Fig. 1D). Ivabradine at 0.1-10 $\mu \mathrm{M}$ produced intermittent irregular rhythms with AP block in 4 out of 6 HF SANs (67\%), but not in control SANs (Fig. 1E).

$\mathrm{KN}-93$ at $3 \mu \mathrm{M}$ decreased the beating rates of control and HF SANs compared with baseline (Fig. 2A-D). KN-93 (at $3 \mu \mathrm{M})$ decreased the beating rate in control and HF SANs by
Table I. Echocardiography results in control and HF rabbits.

\begin{tabular}{lccr}
\hline Parameter & Control $(\mathrm{n}=6)$ & HF $(\mathrm{n}=6)$ & P-value \\
\hline LVEF (\%) & $77.8 \pm 2.3$ & $39.2 \pm 2.5$ & $<0.001$ \\
LVIDd (cm) & $1.4 \pm 0.1$ & $1.2 \pm 0.1$ & $<0.001$ \\
LVIDs (cm) & $0.8 \pm 0.1$ & $0.9 \pm 0.1$ & 0.009 \\
FS (\%) & $53 \pm 3$ & $26 \pm 2$ & $<0.001$ \\
LA diameter (mm) & $7.0 \pm 0.6$ & $8.3 \pm 0.8$ & 0.008
\end{tabular}

Values are expressed as the mean \pm standard error of the mean. HF, heart failure; LVEF, left ventricular ejection fraction; LVIDd, left ventricular internal diameter end diastole; LVIDs, left ventricular internal diameter end systole; FS, fractional shortening; LA, left atrial.

a similar extent ( $12 \pm 1$ vs. $20 \pm 12 \%$; P>0.05). KN-93 did not change the APA, MDP or DDR and did not produce any AP block (results not shown) in either control or HF SANs.

As shown in Fig. 3A-D, ryanodine $(3 \mu \mathrm{M})$ decreased the control and HF SAN beating rates by a similar extent $(24 \pm 2$ vs. $32 \pm 13 \%$ at $3 \mu \mathrm{M}, \mathrm{P}>0.05)$. Ryanodine at 0.3 and $3 \mu \mathrm{M}$ did not change the APA or MDP or produce an AP block (results not shown) in control or HF SANs. Higher-dose ryanodine (3 $\mu \mathrm{M})$ decreased the DDR in control and HF SANs.

As shown in Fig. 3E-H, ranolazine at $10 \mu \mathrm{M}$ decreased the beating rates of control and HF SANs by a similar extent $(8 \pm 1$ vs. $16 \pm 4 \%$; $P>0.05)$. Ranolazine did not significantly change the APA, MDP or DDR, and did not produce any AP block in either control or HF SANs.

TTX decreased the beating rate of SANs in the control (at 3 and $10 \mu \mathrm{M}$ ) and $\mathrm{HF}$ (at 1,3 and $10 \mu \mathrm{M}$ ) groups (Fig. 4A-D). Furthermore, TTX reduced the APA in HF SANs, but not in control SANs. High-dose TTX $(10 \mu \mathrm{M})$ significantly decreased the DDR in control SANs, but not in HF SANs. In addition, TTX produced AP block in four preparations (three treated at $1 \mu \mathrm{M}$ and one treated at $3 \mu \mathrm{M})$ out of six samples of HF SANs, but not in control SANs (Fig. 4E).

Protein expression of ionic currents in SANs. SANs from the HF group had lower protein levels of HCN4, RyR, PLB-17 and Nav1.5 than control SANs (Fig. 5). However, SANs from the HF group had a lower ratio of PLB-17 to PLB. HF and control SANs had similar protein expression of CaMKII and SERCA.

\section{Discussion}

Hyperpolarization-activated, cyclic nucleotide-gated cation channels (HCNs) are responsible for the pacemaker current $\left(I_{\mathrm{f}}\right)$ in SAN cells, and remodeling of the $I_{\mathrm{f}}$ can lead to SAN dysfunction $(6,25)$. In an animal study, HF downregulated the expression of the HCN subunit of SANs, which may be responsible for SAN dysfunction (6). HCN overexpression enhances $I_{\mathrm{f}}$-based pacemaking, which may improve SAN function. In agreement with previous studies, the present study also demonstrated that SANs of rabbits with $\mathrm{HF}$ had a lower protein expression of HCN4 compared to SANs of control rabbits. In a clinical study, ivabradine (an inhibitor of the $I_{\mathrm{f}}$ ) significantly reduced major risks associated with $\mathrm{HF}$, which was associated 
A $1 \mathrm{sec}$

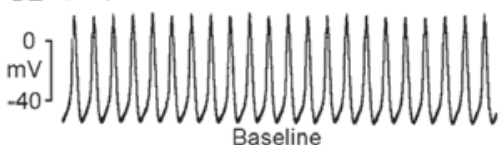

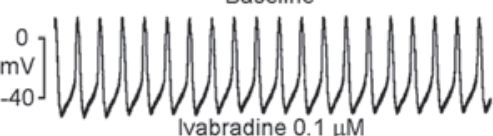
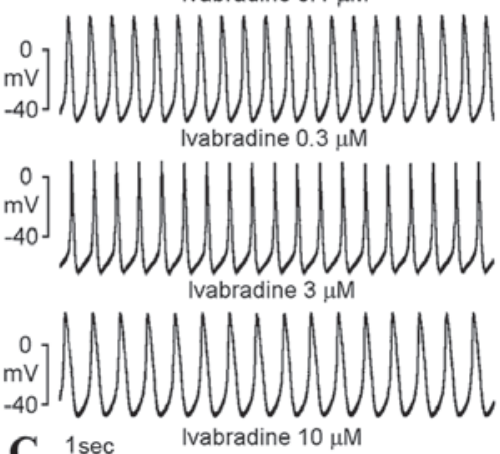

C $1 \mathrm{sec}$
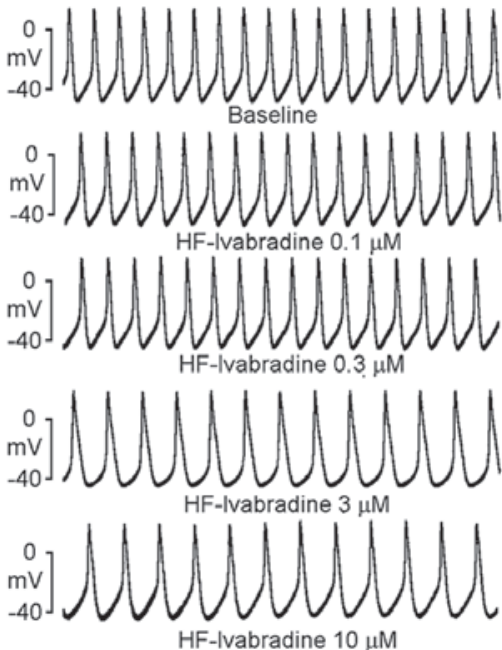

B
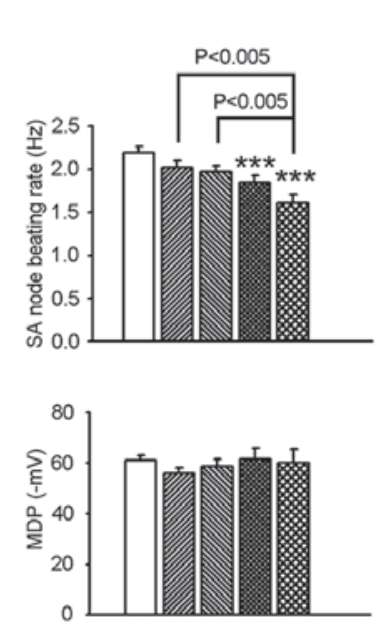

D
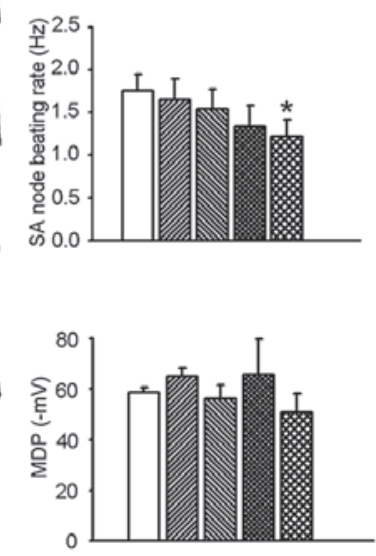
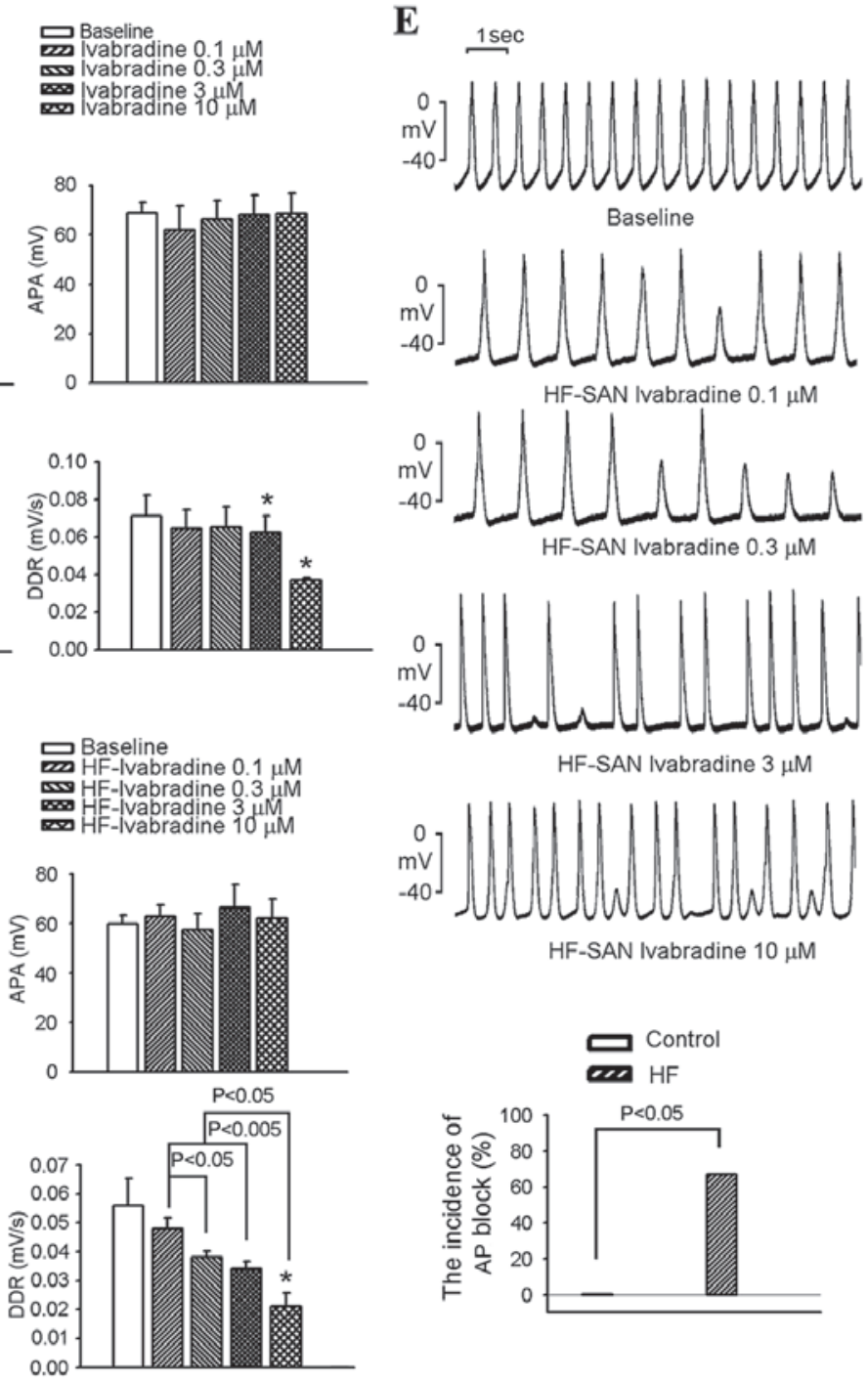

HF-SAN Ivabradine $10 \mu \mathrm{M}$
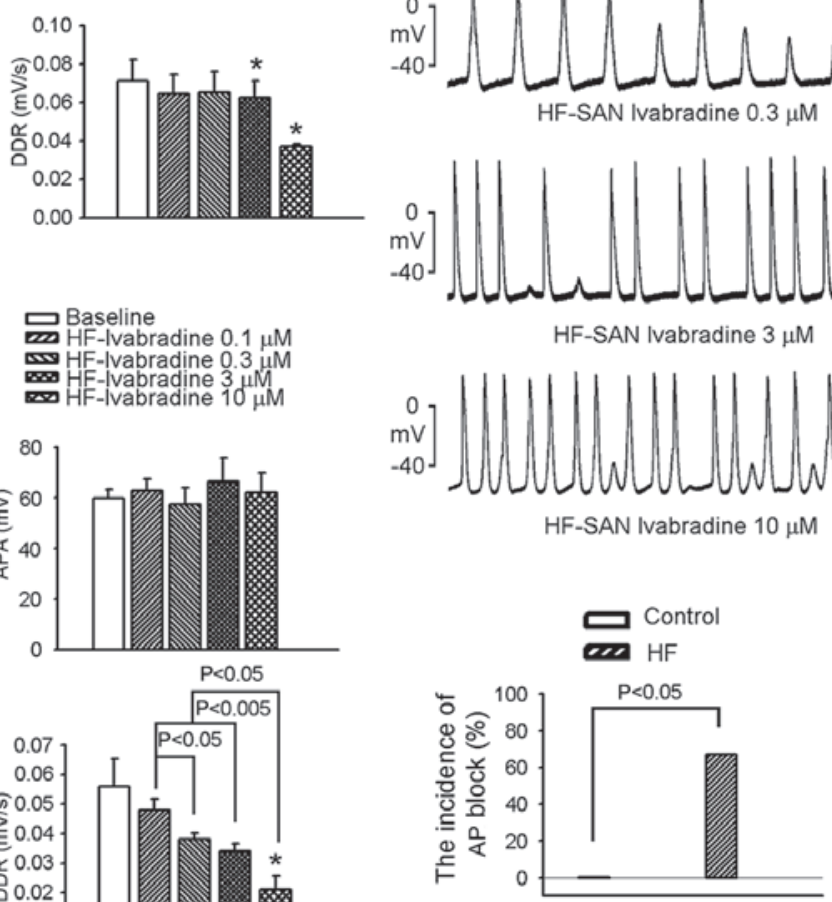

Figure 1. Effects of ivabradine on APs of SANs in the control and HF groups. Panel (A) Representative APs of control SANs prior to and after treatment with ivabradine $(0.1,0.3,3$ and $10 \mu \mathrm{M})$. (B) Average SAN beating rates, APA, MDP and DDR prior to and after treatment with ivabradine $(0.1,0.3,3$ and $10 \mu \mathrm{M})$ in the control group $(\mathrm{n}=6)$. (C) Representative APs of HF SANs prior to and after treatment with ivabradine (0.1, $0.3,3$ and $10 \mu \mathrm{M})$. (D) Average SAN beating rates, APA, MDP and DDR prior to and after treatment with ivabradine (0.1, 0.3, 3 and $10 \mu \mathrm{M})$ in the HF group (n=6). (E) Representative APs and incidence of ivabradine-induced AP block in HF SANs. AP block was defined as an AP with incomplete morphology and a lower amplitude compared that at baseline during the steady-state recording. ${ }^{*} \mathrm{P}<0.05,{ }^{* * *} \mathrm{P}<0.005$ vs. baseline ( $0.03 \%$ dimethyl sulfoxide). AP, action potential; APA, AP amplitude; HF, heart failure; SAN, sinoatrial node; MDP, maximum diastolic potential; DDR, diastolic depolarization rate.

with a decrease in the heart rate (7). However, symptomatic and asymptomatic bradycardia was more frequent $(10 \%)$ in the ivabradine group than in patients taking a placebo. A recentstudy showed that ivabradine completely eliminated inappropriate sinus tachycardia in $\sim 50 \%$ of patients (26). These findings suggested that ivabradine has the potential to treat HF and inappropriate sinus tachycardia. The present study demonstrated that control and HF SANs had different sensitivities to ivabradine. Furthermore, ivabradine produced AP block in HF SANs, but not in control SANs. These findings suggested that administration of ivabradine may possibly cause SAN block in the failing heart.

Yanni et al (2) reported that the expression of ryanodine receptor 2 and ryanodine receptor 3, types 1-3 inositol 1,4,5-trisphosphate (IP3) receptors, calsequestrin 2 (SR $\mathrm{Ca}^{2+}$-binding protein) and plasma membrane $\mathrm{Ca}^{2+}$-ATPase 1 significantly increased in the SAN but not in atrial tissue during HF. Therefore, dysregulated calcium handling may be the cause of SAN dysfunction in HF models. In the present study, HF and control SANs had similar protein expression levels of CaMKII and SERCA; however, HF SANs had a lower protein expression of RyR. Furthermore, ratio of phosphorylated PBL to PBL was decreased in HF compared with control SANs, which may inhibit the reuptake of intracellular calcium by SERCA and further alter the regulation of the $\mathrm{Ca}^{2+}$ clock. The present study also showed that a high dose of ryanodine $(3 \mu \mathrm{M})$ reduced the beating rate of normal and HF SANs. The lower protein expression of RyR in HF SANs may cause RyR dysfunction.

SCN5A mutations lead to reductions in $I_{\mathrm{Na}}$, which may decrease the pacemaker rate and reduce the conduction velocity of SAN APs, resulting in AP block characterized as sick sinus syndrome (14). In line with this, the present study found that HF SANs had a lower protein expression of Nav1.5, 
A $\stackrel{1 \mathrm{sec}}{\longrightarrow}$
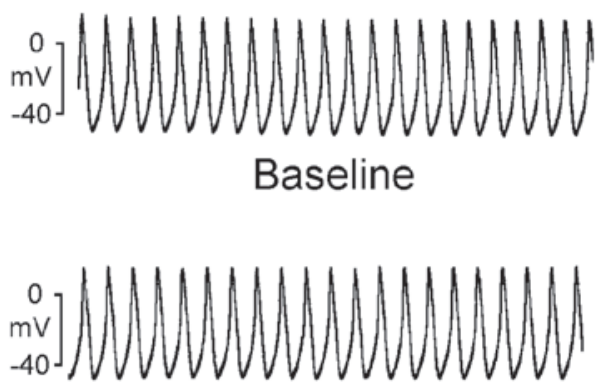

$\mathrm{KN}-930.3 \mu \mathrm{M}$

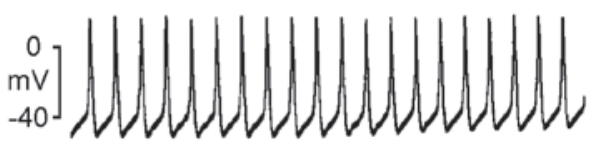

$\mathrm{KN}-933 \mu \mathrm{M}$

C $\stackrel{1 \mathrm{sec}}{\longrightarrow}$

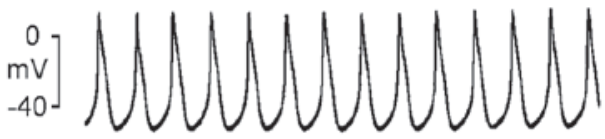

Baseline

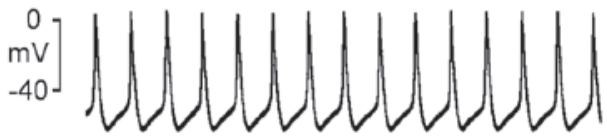

HF-SAN KN-93 $0.3 \mu \mathrm{M}$

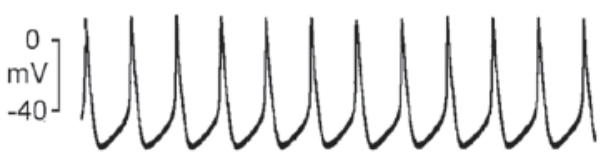

HF-SAN KN-93 $3 \mu \mathrm{M}$
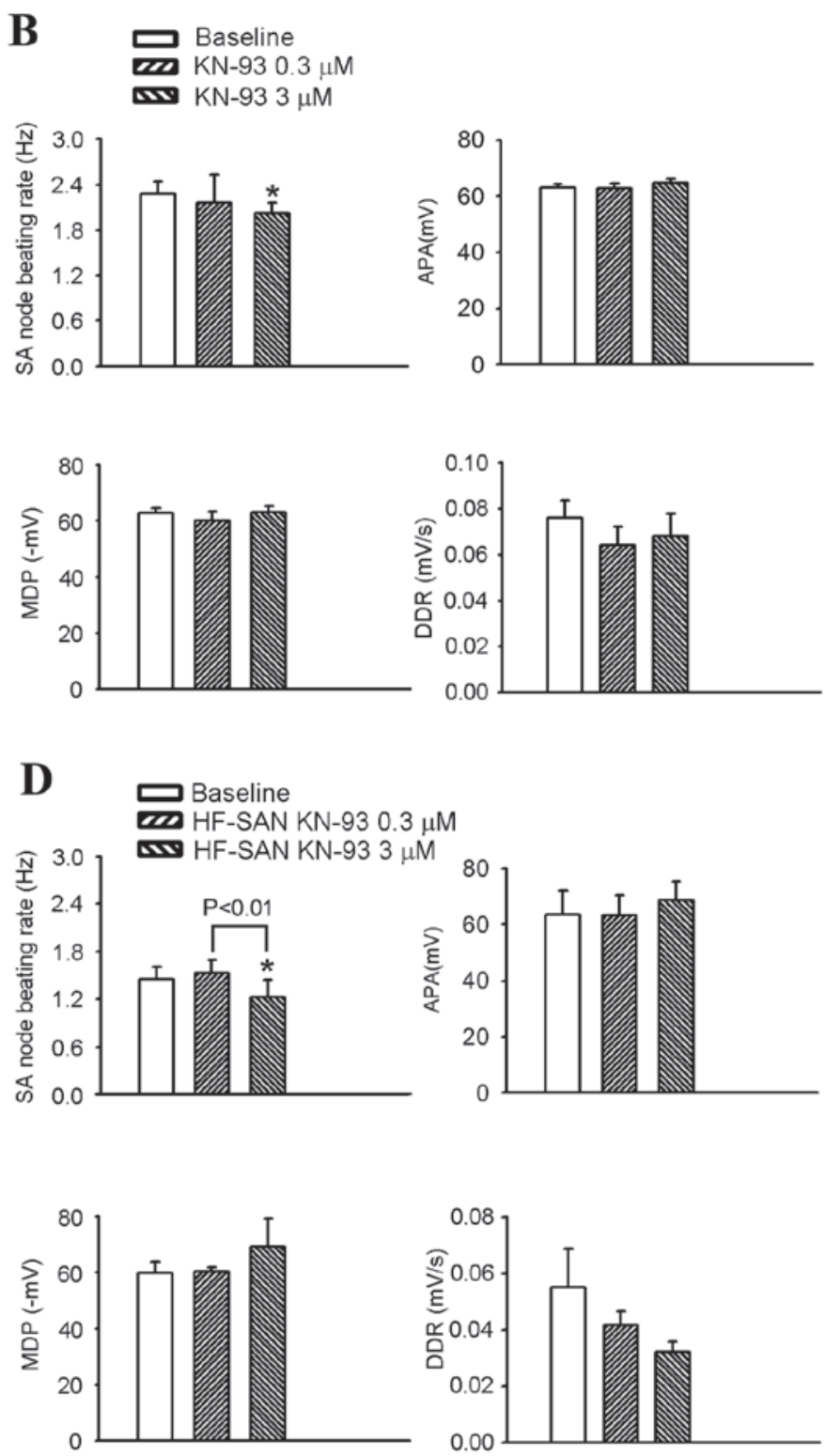

Figure 2. Effects of KN-93 on APs of SANs in the control and HF groups. (A) Representative APs of control SANs prior to and after treatment with KN-93 $(0.3$ and $3 \mu \mathrm{M})$. (B) Average SAN beating rates, APA, MDP and DDR prior to and after treatment with KN-93 (0.3 and $3 \mu \mathrm{M})$ in the control group (n=6). (C) Representative APs of HF SANs prior to and after treatment with KN-93 (0.3 and $3 \mu \mathrm{M})$. (D) Average SAN beating rates, APA, MDP and DDR prior to and after treatment with $\mathrm{KN}-93(0.3$ and $3 \mu \mathrm{M})$ in the HF group $(\mathrm{n}=6)$. ${ }^{*} \mathrm{P}<0.05$ vs. baseline $(0.03 \%$ dimethyl sulfoxide). AP, action potential; APA, AP amplitude; $\mathrm{HF}$, heart failure; SAN, sinoatrial node; MDP, maximum diastolic potential; DDR, diastolic depolarization rate.

which is an $I_{\mathrm{Na}}$-associated protein, compared with normal SANs. The effects of TTX on reducing the beating rate and APA were more prominent in HF SANs. TTX caused AP block in HF SANs, but not in normal SANs, suggesting a causative association between impaired $I_{\mathrm{Na}}$ and SAN dysfunction in this HF model.

In a pacing-induced HF model, decreased peak $I_{\mathrm{Na}}$ and increased $I_{\mathrm{Na} \text {-Late }}$ caused a prolongation of APs and genesis of arrhythmia. Enhanced $I_{\text {Na-Late }}$ leads to intracellular $\mathrm{Na}^{+}$ loading, which elevates intracellular $\mathrm{Ca}^{2+}$ through the $\mathrm{Na}^{+} / \mathrm{Ca}^{2+}$ exchanger, inducing a $\mathrm{Ca}^{2+}$-dependent transient inward current and triggering activity $(16,20,27)$. However, to the best of our knowledge, the impact of the $I_{\text {Na-Late }}$ on SANs has not yet been studied. In the clinic, ranolazine is used to attenuate the $\mathrm{Na}$-dependent $\mathrm{Ca}$ overload through inhibiting the $I_{\text {Na-Late }}$ and promoting diastolic tension and oxygen handling during myocardial ischemia, which can act as an anti-anginal agent (17). Ranolazine was reported to have anti-arrhythmic effects in studies on ischemia and $\operatorname{HF}(28,29)$. However, the electropharmacological effects of ranolazine on SANs from patients with HF have remained elusive. The present study demonstrated that ranolazine inhibits SANs from HF and control rabbits, suggesting that the $I_{\mathrm{Na} \text {-Late }}$ may have a role in the electrophysiology of SANs.

HF contributes to electrical remodeling in the SAN, leading to SAN dysfunction. For the first time, the present study applied blockers of various ion channels and compared changes of electrophysiological responses between SANs isolated from control and HF rabbits. The results suggested that HF can modulate the spontaneous activity of the SAN as well as its response to various pharmacological interventions. These findings provide novel insight into the mechanisms of HF-induced 


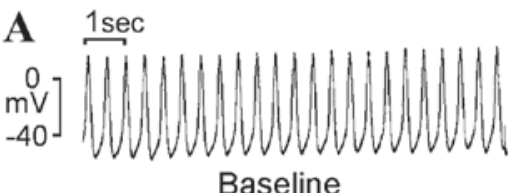

Baseline

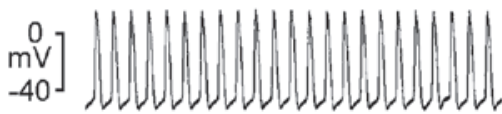

Ryanodine $0.3 \mu \mathrm{M}$

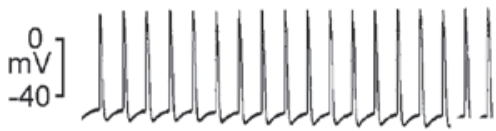

Ryanodine $3 \mu \mathrm{M}$
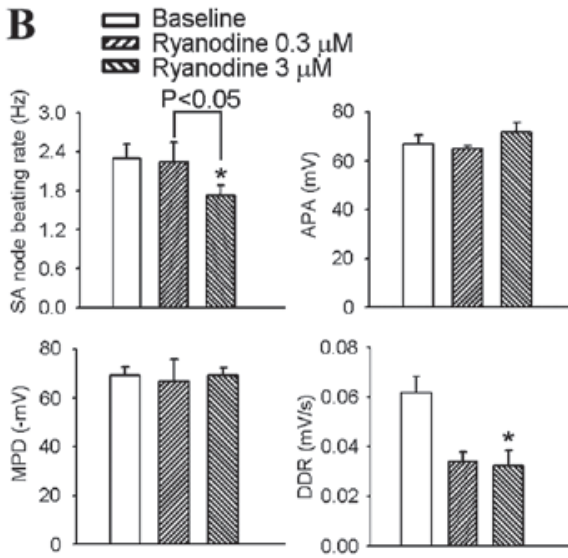

E $1 \mathrm{sec}$

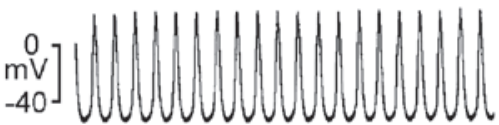

Baseline

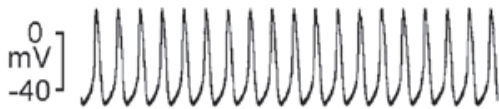

Ranolazine $10 \mu \mathrm{M}$

F Baseline $10 \mu \mathrm{M}$ $P<0.005$
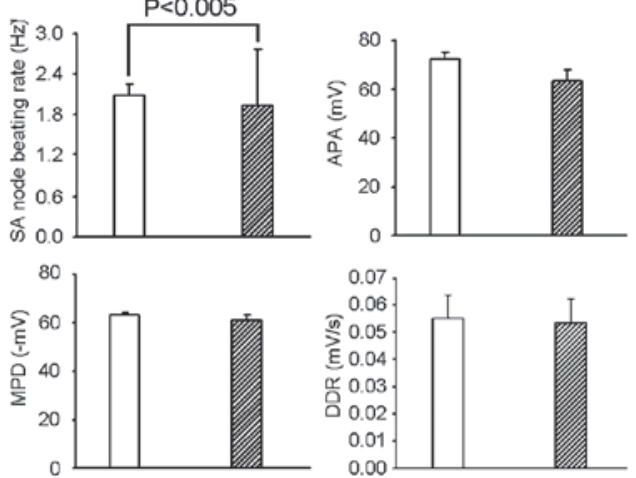

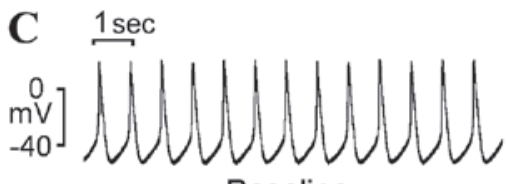

Baseline

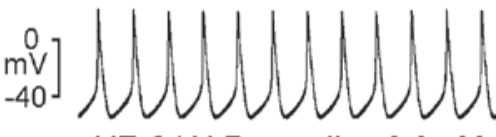

HF-SAN Ryanodine $0.3 \mu \mathrm{M}$

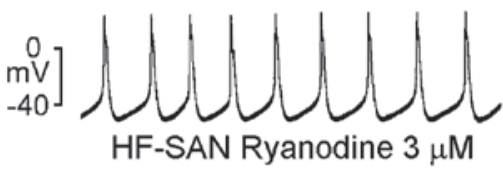

\section{Baseline \\ m HF-SAN Ryanodine $0.3 \mu \mathrm{M}$}
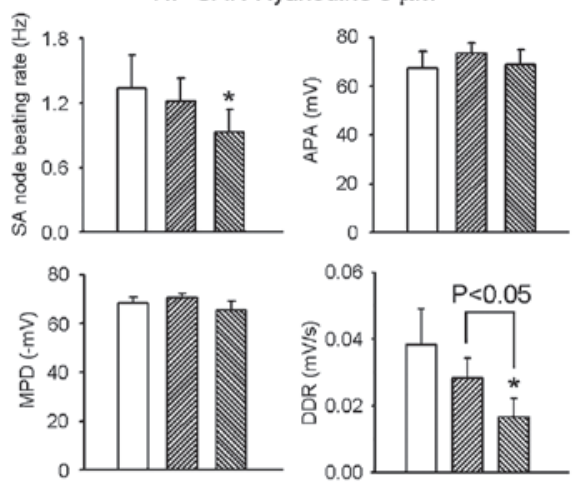

G $1 \mathrm{sec}$

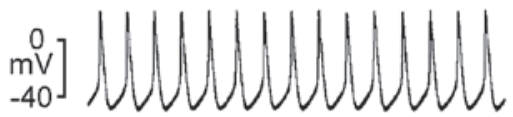

Baseline

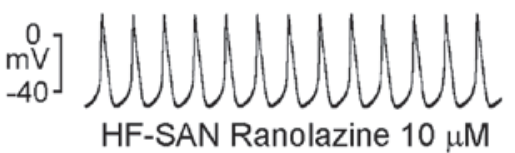

H D Baseline
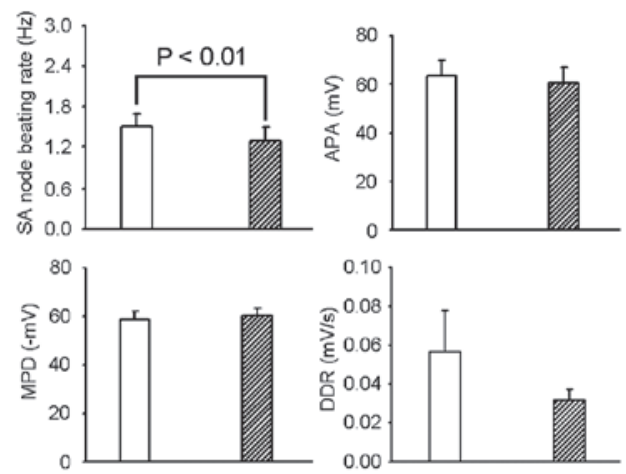

Figure 3. Effects of ryanodine and Ran on APs of SANs in the control and HF groups. (A) Representative APs of control SANs prior to and after treatment with ryanodine $(0.3$ and $3 \mu \mathrm{M})$. (B) Average SAN beating rates, APA, MDP and DDR prior to and after treatment with ryanodine (0.3 and $3 \mu \mathrm{M})$ in the control group ( $n=6)$. (C) Representative APs of HF SANs prior to and after treatment with ryanodine (0.3 and $3 \mu \mathrm{M})$. (D) Average SAN beating rates, APA, MDP and DDR prior to and after treatment with ryanodine $(0.3$ and $3 \mu \mathrm{M})$ in the HF group $(\mathrm{n}=6)$. (E) Representative APs of control SANs prior to and after treatment with Ran $(10 \mu \mathrm{M})$. (F) Average SAN beating rates, APA, MDP and DDR prior to and after treatment with Ran (10 $\mu \mathrm{M})$ infusion in the control group (n=6). (G) Representative APs of HF SANs prior to and after treatment with Ran $(10 \mu \mathrm{M})$. (H) Average SAN beating rates, APA, MDP and DDR prior to and after treatment with Ran $(10 \mu \mathrm{M})$ in the HF group $(\mathrm{n}=6)$. ${ }^{*} \mathrm{P}<0.05$ vs. baseline $(0.03 \%$ dimethyl sulfoxide) of ryanodine. AP, action potential; APA, AP amplitude; $\mathrm{HF}$, heart failure; SAN, sinoatrial node; MDP, maximum diastolic potential; DDR, diastolic depolarization rate; Ran, ranolazine. 
A $\stackrel{1 \mathrm{sec}}{\stackrel{1}{1}}$
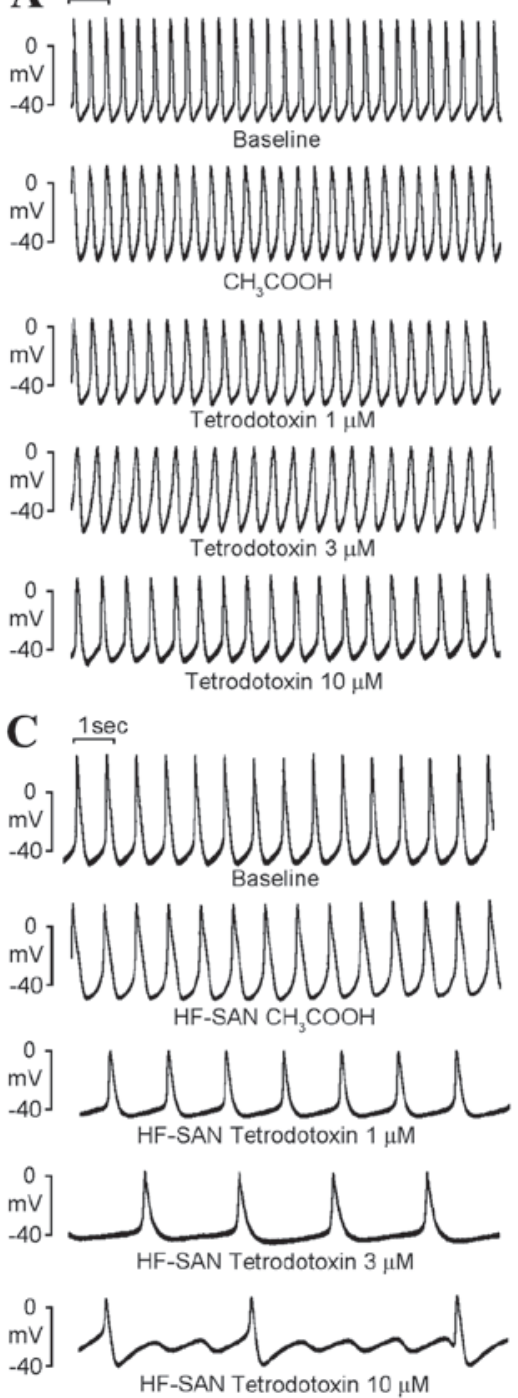
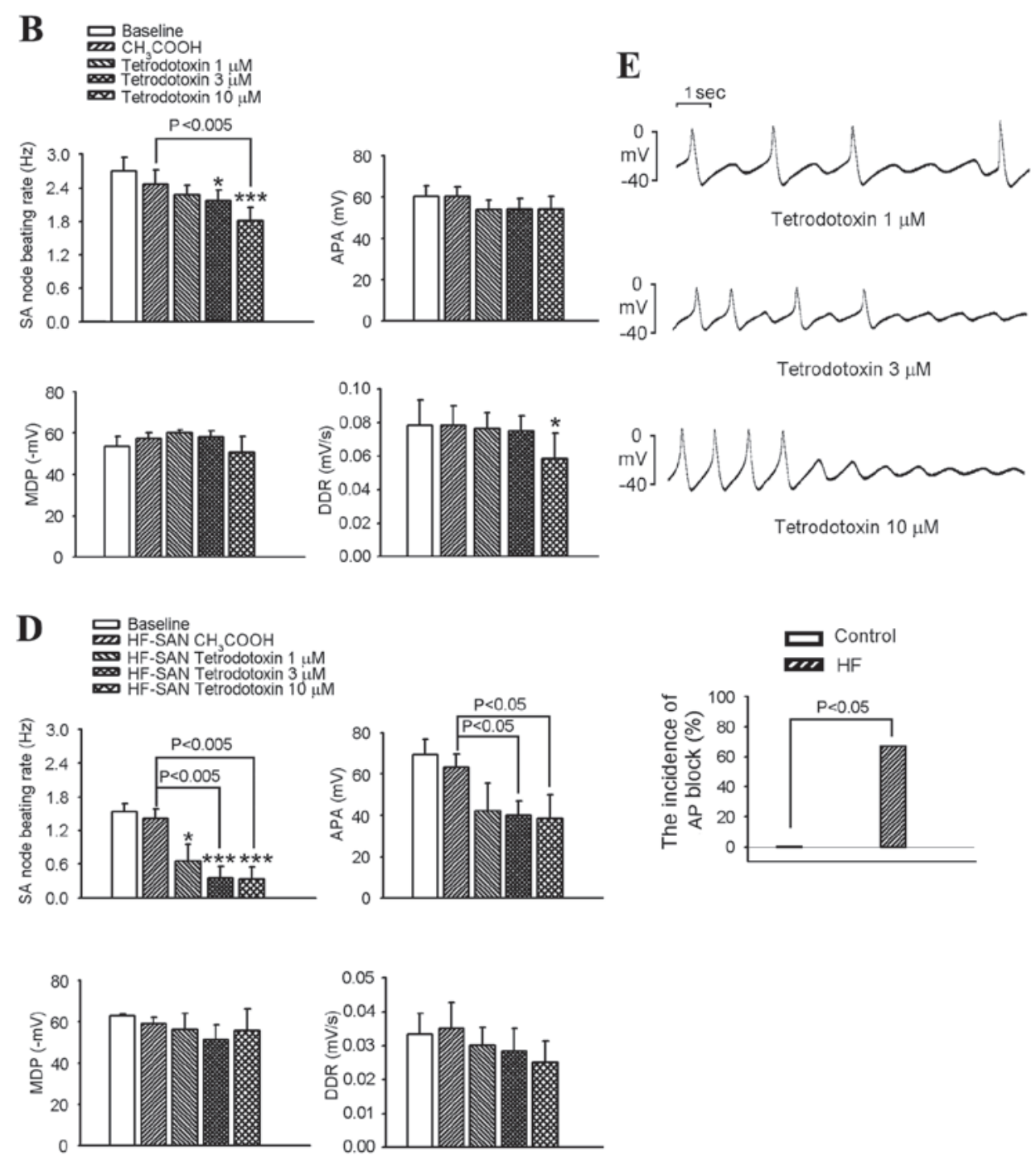

Figure 4. Effects of TTX on APs of SANs in the control and HF groups. (A) Representative APs of control SANs at baseline, after treatment with 0.01\% acetic acid and under TTX (1, 3 and $10 \mu \mathrm{M})$ infusion. (B) Average SAN beating rates, APA, MDP and DDR at baseline, after treatment with $0.01 \%$ acetic acid and under a TTX $(1,3$ and $10 \mu \mathrm{M})$ infusion in the control group $(\mathrm{n}=6)$. (C) Representative APs of HF SANs at baseline, after treatment with $0.01 \%$ acetic acid and under TTX $(1,3$ and $10 \mu \mathrm{M})$ infusion. (D) Average SAN beating rates, APA, MDP and DDR at baseline, after treatment with $0.01 \%$ acetic acid and under a TTX $(1,3$ and $10 \mu \mathrm{M})$ infusion in the HF group $(\mathrm{n}=6)$. (E) AP block of SANs at baseline, after treatment with $0.01 \%$ acetic acid and under TTX $(1,3$ and $10 \mu \mathrm{M})$ infusion in HF rabbits (n=6). AP block was defined as an AP with incomplete morphology and a lower amplitude compared that at baseline during the steady-state recording. ${ }^{*} \mathrm{P}<0.05,{ }^{* * *} \mathrm{P}<0.005$ vs. baseline. AP, action potential; APA, AP amplitude; HF, heart failure; SAN, sinoatrial node; MDP, maximum diastolic potential; DDR, diastolic depolarization rate; TTX, tetrodotoxin.

SAN dysfunction, which may aid in the prevention of sick sinus syndrome during the process of $\mathrm{HF}$, and warrants further study.

Of note, the present study had certain limitations. The rapid and slow delayed rectifier potassium current $\left(I_{\mathrm{Kr}}\right.$ and $\left.I_{\mathrm{Ks}}\right)$ has a prominent role in the SAN. $I_{\mathrm{Kr}}$ is the major factor determining the maximum diastolic potential and ensures the firing of the subsequent AP in the SAN (30). In the SAN of HF rabbits, $I_{\mathrm{f}}$ and $I_{\mathrm{Ks}}$ were reduced by 40 and $20 \%$, respectively (31). $I_{\mathrm{Ks}}$ has a minimal effect on pacemaker activity and the HF-induced reduction of the heart rate is mainly induced by remodeling of the $I_{\mathrm{f}}$. While the present study did not investigate the effects of HF on the $I_{\mathrm{Kr}}$ and $I_{\mathrm{Ks}}$ of SANs, ranolazine has $I_{\mathrm{Kr}}$-inhibiting capacity $\left(\mathrm{IC}_{50}=12 \mu \mathrm{M}\right)(17)$. The dose of ranolazine $(10 \mu \mathrm{M})$ used in the present study may have inhibited $I_{\mathrm{Na} \text {-Late }}$ as well as $I_{\mathrm{Kr}}$. Moreover, the present study used KN93 to block CaMKII, which also possesses L-type calcium current blocking activity (32). Yaniv et al (33) studied the CaMKII activity in rabbit SANs and demonstrated that KN-92 (a blocker of L-type calcium current, but not CaMKII) has no effect on the electrical activity of SANs. Therefore, the effects of KN-93 on the electrical activities of SAN found in the present study are likely to be caused by CaMKII inhibition. Furthermore, in the HF group properties of diseased tissue may have caused relatively large standard error in the values of AP parameters, which may have led to no significance being observed in comparison with the control group.

In conclusion, HF modulates the electropharmacological responses of the SAN by channel regulation, which may result in SAN dysfunction associated with HF. Furthermore, altered pharmacological responses in SANs from rabbits with HF suggest that anti-arrhythmic drugs pose a pro-arrhythmic risk in HF and as such, should be used with caution. 

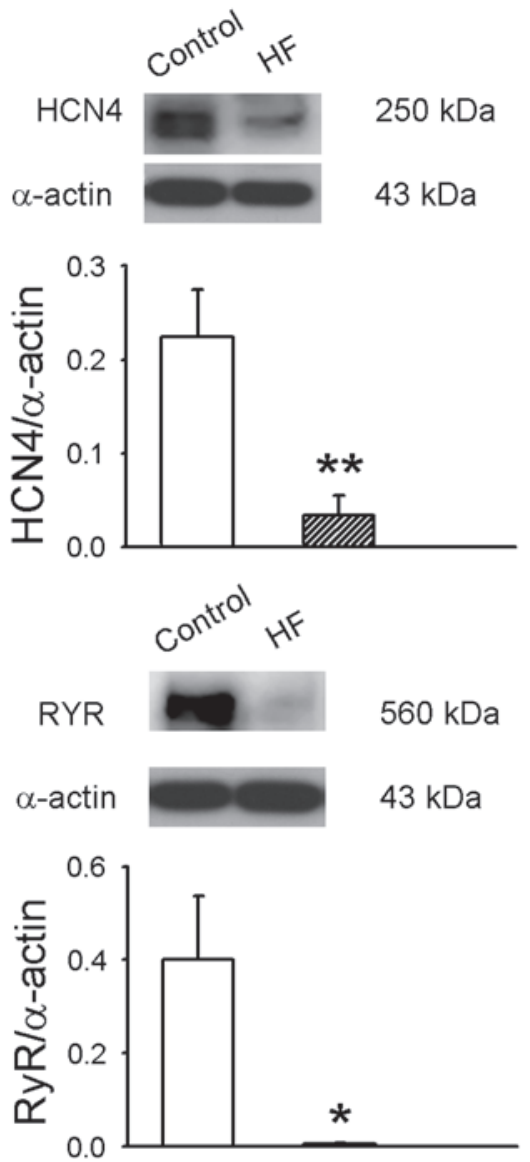
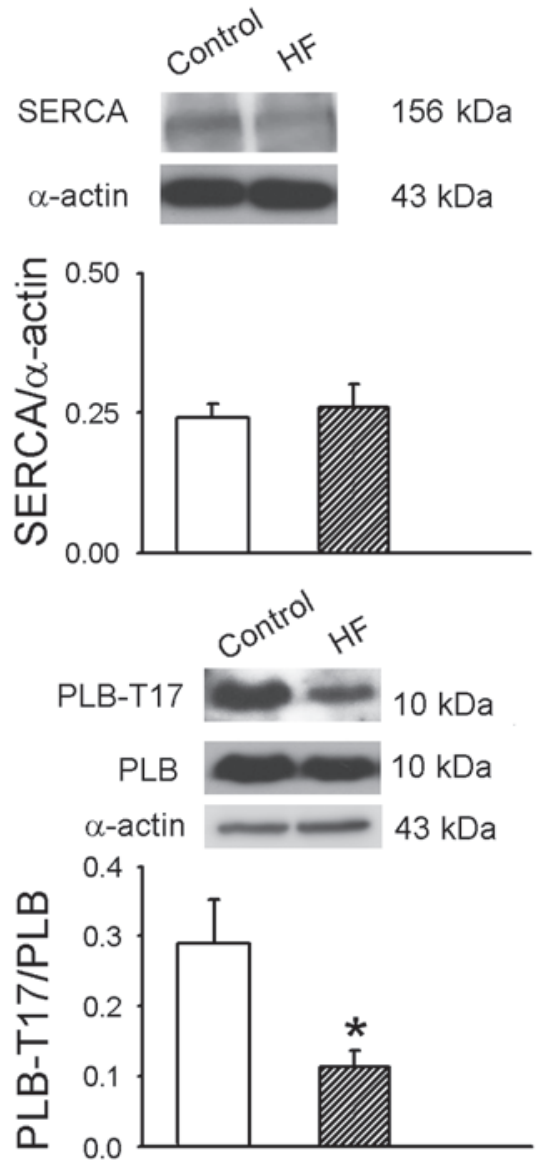
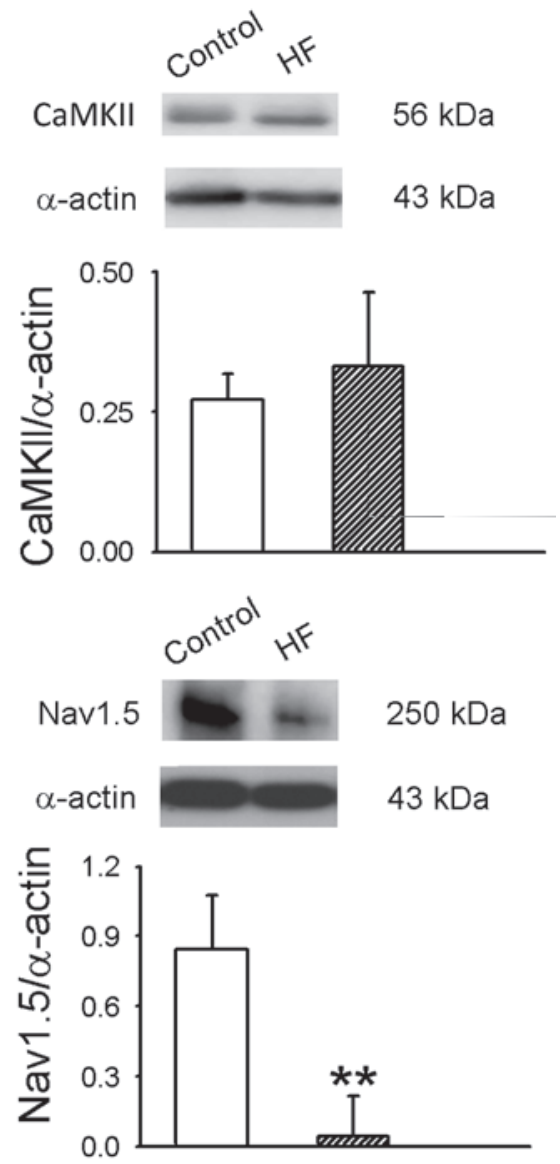

Figure 5. Protein expression of HCN4, CaMKII, SERCA2a, phospholamban (PLB), PLB-T17, RyR and Nav1.5 in sinoatrial nodes from control rabbits and those with $\mathrm{HF}$ ( $\mathrm{n}=6$ per group) was analyzed by western blot analysis. $\alpha$-Sarcomeric actin was used as a loading control. ${ }^{*} \mathrm{P}<0.05$, ${ }^{* *} \mathrm{P}<0.01 \mathrm{vs}$. control. $\mathrm{HF}$, heart failure; HCN4, hyperpolarization-activated cyclic nucleotide-gated potassium channel 4; CaMKII, calmodulin kinase II; SERCA2a, sarcoplasmic reticulum $\mathrm{Ca}^{2+}$-ATPase; PLB, phospholamban; PLB-T17, phosphorylated PLB; Ryr, ryanodine receptor; Nav1.5, sodium channel, voltage-gated, type V.

\section{Acknowledgements}

The present study was supported by grants from Taipei Medical University-Wan Fang Hospital (nos. 102-wf-eva-15 and 104swf02), the National Science Council of Taiwan (nos. NS C100-2314-B-075-046-MY3, NSC101-2314-B-010-057-MY3 and NSC101-2314-B-075-056-MY3), Taipei Veteran General Hospital (nos. V102C-054, V102E7-002 and VGHUST102-G1-1-1) and Chang-Gung Memorial Hospital (no. CMRPG3A0571-3).

\section{References}

1. Sanders P, Morton JB, Davidson NC, Spence SJ, Vohra JK, Sparks PB and Kalman JM: Electrical remodeling of the atria in congestive heart failure: Electrophysiological and electroanatomic mapping in humans. Circulation 108: 1461-1468, 2003.

2. Yanni J, Tellez JO, Maczewski M, Mackiewicz U, Beresewicz A, Billeter R, Dobrzynski H and Boyett MR: Changes in ion channel gene expression underlying heart failure-induced sinoatrial node dysfunction. Circ Heart Fail 4: 496-508, 2011.

3. Dobrzynski H, Boyett MR and Anderson RH: New insights into pacemaker activity: Promoting understanding of sick sinus syndrome. Circulation 115: 1921-1932, 2007.

4. Stevenson WG, Stevenson LW, Middlekauff HR and Saxon LA: Sudden death prevention in patients with advanced ventricular dysfunction. Circulation 88: 2953-2961, 1993.

5. Opthof T, Coronel R, Rademaker HM, Vermeulen JT, Wilms-Schopman FJ and Janse MJ: Changes in sinus node function in a rabbit model of heart failure with ventricular arrhythmias and sudden death. Circulation 101: 2975-2980, 2000.
6. Zicha S, Fernández-Velasco M, Lonardo G, L'Heureux N and Nattel S: Sinus node dysfunction and hyperpolarization-activated (HCN) channel subunit remodeling in a canine heart failure model. Cardiovasc Res 66: 472-481, 2005.

7. Swedberg K, Komajda M, Böhm M, Borer JS, Ford I, Dubost-Brama A, Lerebours G and Tavazzi L; SHIFT Investigators: Ivabradine and outcomes in chronic heart failure (SHIFT): A randomised placebo-controlled study. Lancet 376: 875-885, 2010.

8. Shinohara T, Park HW, Han S, Shen MJ, Maruyama M, Kim D, Chen PS and Lin SF: $\mathrm{Ca}^{2+}$ clock malfunction in a canine model of pacing-induced heart failure. Am J Physiol Heart Circ Physiol 299: H1805-H1811, 2010.

9. Swaminathan PD, Purohit A, Soni S, Voigt N, Singh MV, Glukhov AV, Gao Z, He BJ, Luczak ED, Joiner ML, et al: Oxidized CaMKII causes cardiac sinus node dysfunction in mice. J Clin Invest 121: 3277-3288, 2011.

10. Swaminathan PD, Purohit A, Hund TJ and Anderson ME: Calmodulin-dependent protein kinase II: linking heart failure and arrhythmias. Circ Res 110: 1661-1677, 2012.

11. Yano M, Kobayashi S, Kohno M, Doi M, Tokuhisa T, Okuda S, Suetsugu M, Hisaoka T, Obayashi M, Ohkusa T, et al: FKBP12.6-mediated stabilization of calcium-release channel (ryanodine receptor) as a novel therapeutic strategy against heart failure. Circulation 107: 477-484, 2003

12. Toischer K, Lehnart SE, Tenderich G, Milting H, Körfer R, Schmitto JD, Schondube FA, Kaneko N, Loughrey CM, Smith GL, et al: K201 improves aspects of the contractile performance of human failing myocardium via reduction in $\mathrm{Ca} 2+$ leak from the sarcoplasmic reticulum. Basic Res Cardiol 105: 279-287, 2010.

13. Hunt DJ, Jones PP, Wang R, Chen W, Bolstad J, Chen K, Shimoni Y and Chen SR: K201 (JTV519) suppresses spontaneous $\mathrm{Ca}^{2+}$ release and $[3 \mathrm{H}]$ ryanodine binding to RyR2 irrespective of FKBP12.6 association. Biochem J 404: 431-438, 2007. 
14. Butters TD, Aslanidi OV, Inada S, Boyett MR, Hancox JC, Lei M and Zhang $\mathrm{H}$ : Mechanistic links between $\mathrm{Na}^{+}$channel (SCN5A) mutations and impaired cardiac pacemaking in sick sinus syndrome. Circ Res 107: 126-137, 2010.

15. Wu J, Zhang Y, Zhang X, Cheng L, Lammers WJ, Grace AA, Fraser JA, Zhang H, Huang CL and Lei M: Altered sinoatrial node function and intra-atrial conduction in murine gain-of-function Scn $5 a+/ \Delta \mathrm{KPQ}$ hearts suggest an overlap syndrome. Am J Physiol Heart Circ Physiol 302: H1510-H1523, 2012.

16. Valdivia CR, Chu WW, Pu J, Foell JD, Haworth RA, Wolff MR, Kamp TJ and Makielski JC: Increased late sodium current in myocytes from a canine heart failure model and from failing human heart. J Mol Cell Cardiol 38: 475-483, 2005.

17. Sossalla S and Maier LS: Role of ranolazine in angina, heart failure, arrhythmias, and diabetes. Pharmacol Ther 133: 311-323, 2012.

18. Morrow DA, Scirica BM, Sabatine MS, de Lemos JA, Murphy SA, Jarolim P, Theroux P, Bode C and Braunwald E: B-type natriuretic peptide and the effect of ranolazine in patients with non-ST-segment elevation acute coronary syndromes: Observations from the MERLIN-TIMI 36 (Metabolic Efficiency With Ranolazine for Less Ischemia in Non-ST Elevation Acute Coronary-Thrombolysis In Myocardial Infarction 36) trial. J Am Coll Cardiol 55: 1189-1196, 2010.

19. Tsuji Y,Zicha S, Qi XY,Kodama I and Nattel S: Potassium channel subunit remodeling in rabbits exposed to long-term bradycardia or tachycardia: Discrete arrhythmogenic consequences related to differential delayed-rectifier changes. Circulation 113: 345-355, 2006.

20. Chang SL, Chen YC, Yeh YH, Lin YK, Wu TJ, Lin CI, Chen SA and Chen YJ: Heart failure enhanced pulmonary vein arrhythmogenesis and dysregulated sodium and calcium homeostasis with increased calcium sparks. J Cardiovasc Electrophysiol 22 1378-1386, 2011.

21. Verheijck EE, Wessels A, van Ginneken AC, Bourier J, Markman MW, Vermeulen JL, de Bakker JM, Lamers WH, Opthof T and Bouman LN: Distribution of atrial and nodal cells within the rabbit sinoatrial node: Models of sinoatrial transition. Circulation 97: 1623-1631, 1998.

22. Chang SL, Chen YC, Chen YJ, Wangcharoen W, Lee SH, Lin CI and Chen SA: Mechanoelectrical feedback regulates the arrhythmogenic activity of pulmonary veins. Heart 93: 82-88, 2007.

23. Chang SL, Chen YC, Yeh YH, Lai YJ, Yeh HI, Lin CI, Lin YK, Lin YJ, Wu TJ, Huang YK, et al: Heart failure enhances arrhythmogenesis in pulmonary veins. Clin Exp Pharmacol Physiol 38: 666-674, 2011
24. Tsai CF, Chen YC, Lin YK, Chen SA and Chen YJ: Electromechanical effects of the direct renin inhibitor (aliskiren) on the pulmonary vein and atrium. Basic Res Cardiol 106: 979-993, 2011

25. Huang X, Yang P, Du Y, Zhang J and Ma A: Age-related down-regulation of $\mathrm{HCN}$ channels in rat sinoatrial node. Basic Res Cardiol 102: 429-435, 2007.

26. Cappato R, Castelvecchio S, Ricci C, Bianco E, Vitali-Serdoz L, Gnecchi-Ruscone T, Pittalis M, De Ambroggi L, Baruscotti M, Gaeta M, et al: Clinical efficacy of ivabradine in patients with inappropriate sinus tachycardia: A prospective, randomized, placebo-controlled, double-blind, crossover evaluation. J Am Coll Cardiol 60: 1323-1329, 2012.

27. Song Y, Shryock JC and Belardinelli L: An increase of late sodium current induces delayed afterdepolarizations and sustained triggered activity in atrial myocytes. Am J Physiol Heart Circ Physiol 294: H2031-H2039, 2008.

28. Sossalla S, Kallmeyer B, Wagner S, Mazur M, Maurer U, Toischer K, Schmitto JD, Seipelt R, Schöndube FA, Hasenfuss $\mathrm{G}$, et al: Altered $\mathrm{Na}(+)$ currents in atrial fibrillation effects of ranolazine on arrhythmias and contractility in human atrial myocardium. J Am Coll Cardiol 55: 2330-2342, 2010.

29. Sossalla S, Wagner S, Rasenack EC, Ruff H, Weber SL, Schondube FA, Tirilomis T, Tenderich G, Hasenfuss G, Belardinelli L and Maier LS: Ranolazine improves diastolic dysfunction in isolated myocardium from failing human hearts-role of late sodium current and intracellular ion accumulation. J Mol Cell Cardiol 45: 32-43, 2008.

30. Ono $\mathrm{K}$ and Ito $\mathrm{H}$ : Role of rapidly activating delayed rectifier $\mathrm{K}^{+}$ current in sinoatrial node pacemaker activity. Am J Physiol 269: H453-H462, 1995.

31. Verkerk AO, Wilders R, Coronel R, Ravesloot JH and Verheijck EE: Ionic remodeling of sinoatrial node cells by heart failure. Circulation 108: 760-766, 2003.

32. Anderson ME, Braun AP, Wu Y, Lu T, Wu Y, Schulman H and Sung RJ: KN-93, an inhibitor of multifunctional $\mathrm{Ca}^{++} /$calmodulin-dependent protein kinase, decreases early afterdepolarizations in rabbit heart. J Pharmacol Exp Ther 287: 996-1006, 1998.

33. Yaniv Y, Spurgeon HA, Ziman BD and Lakatta EG: $\mathrm{Ca}^{2+} / \mathrm{calmod}-$ ulin-dependent protein kinase II (CaMKII) activity and sinoatrial nodal pacemaker cell energetics. PLoS One 8: e57079, 2013. 